\title{
Asian-Australians: quiet migration or immigration indigestion?
}

Edition 5, 2021

DOI: 10.37839/MAR2652-550X5.24

\section{Webinar panellists}

\section{Dr Ryan Gustafsson, AKS Postdoctoral Fellow, Asia Institute, University of Melbourne}

Dr Gustafsson presents his research on the approximately 3,600 South Korean children who have been adopted to Australia since 1969, making them the largest cohort of intercountry adoptees in Australia. Referred to by demographers as the 'quiet' or 'unknown' migration, transnational or intercountry adoption has tended to sit uneasily within, and has sometimes been excluded from, accounts of migration. Research suggests that South Korean adoptees inhabit and negotiate multiple social positions and identities.

\section{Dr Qiuping Pan, Research Fellow, Centre for Contemporary Chinese Studies, Asia Institute, University of Melbourne}

Dr Pan presents on how the outbreak of COVID-19 has caused a surge of Sinophobia and anti-Asian racism in Australia and elsewhere. Addressing the deep-seated immigration 'indigestion' issue is not merely about giving immigrants a 'fair go' to realise their social and economic potential; it is also about helping Australia to reap the full developmental and societal benefits of migration. 


\section{Introduction}

Dr Jay Song, Senior Lecturer in Korean Studies, Asia Institute, University of Melbourne.

\section{Chair}

Melissa Conley Tyler, Research Fellow, Asia Institute, University of Melbourne.

Image: Chinese Lunar New Year, Melbourne. Credit: Chris Phutully/Flickr. 